\title{
The Adoption of New Ecommerce Technologies in Romanian SME
}

\author{
Valentin-Andrei Mănescu' ${ }^{1}$, Gheorghe Militaru², Andreea Barbu ${ }^{3}$, Ramona-Alexandra Neghină ${ }^{4}$, \\ Dragoș-Georgian Ilie ${ }^{5}$ \\ ${ }^{1}$ Webecom S.R.L. \\ ${ }^{2}$ Politehnica University of Bucharest \\ ${ }^{3}$ Politehnica University of Bucharest \\ ${ }^{4}$ Webecom S.R.L. \\ ${ }^{5}$ University of Bucharest
}

\begin{abstract}
Romanian companies are expanding in the online environment very fast due to high-speed Internet connections and availability of software programmers. Due to the increasing popularity of smartphones, many entrepreneurs have various opportunities to start or extend their online businesses. The increasing number of open APIs provided by local or global suppliers offer many possibilities for digitalizing a company and extending its activity locally or globally with less resources. Billing companies, shipping companies, advertising companies and other ecommerce related companies are developing business software to facilitate the communication between the most popular ecommerce platforms from the local and international market. The research identified which are the most important processes for ecommerce stores and the level of processes digitalization. For obtaining accurate conclusions our quantitative research was applied to ecommerce entrepreneurs from many niches in companies which are based in Romania. Our results can help to understand the current state of the Romanian ecommerce market and if entrepreneurs and managers would improve or invest in new technologies. Fast business digitalization can offer new opportunities for small and medium enterprises in order to extend locally or even globally.
\end{abstract}

Keywords: Online entrepreneurs, Ecommerce research, Ecommerce technology, Business software, Romanian e-tail 


\section{2nd International Academic Conference on MANAGEMENT and ECONOMICS}

\section{Introduction}

The main objective is to determinate the actual state of ecommerce stores and how they are creating added value to the potential customers. The second objective is to identify the markets where entrepreneurs are acting on, which are their strengths and weaknesses, and also in which way they are adopting new technologies. For this research, we measured facts and perceptions based on a quantitative research. The research was addressed to business owners and administrators of Romanian online stores. The objectives of the conducted research are the following: (1) Identifying the current activity volume of manning an online store in Romania, (2) Identifying the average number of employees involved in the online store activity, (3) Researching the size of the digital showcase of products that help to get online orders, (4) Obtaining statistical correlations between the processes that contribute to an online store's activity.

In order to design the questionnaire, we took into consideration both the respondent's experience on how he/she effectively uses the digital ecosystem to generate and obtain added value. According to Briscoe (2009) digital ecosystems are socio-technical, distributed and adaptable, with the ability to organize, scale and sustain, digital ecosystems being inspired by natural ecosystems (Briscoe, 2009). Although difficult to define, performance will be measured from the perspective of the respondent's perception of the current business efficiency. Richard et. al (2009) considers organizational performance to cover three specific areas of a company: (a) financial performance (profit, asset income, return on investments), (b) product performance on the market (sales, market share) and (c) shareholders returns (returns, economical added value) (Richard, et al., 2009).

\section{Methodology}

In order to identify the perception of the respondents regarding their own online store activity and the actual state of existing processes efficiency, two types of questions were used. These types of questions have identified the perception of the value proposition and questions about the current state of its representation in the managed organization. By using these types of questions, it was possible to identify whether in the case of some respondents the cognitive dissonance phenomenon appears. Almoatazbillah Hassan (2012) states that the concept of the value proposition does not have a specific definition, even if the term is used frequently. Thus, it can be defined as a complete set of experiences that the organization provides to the customers, including the value provided for a certain amount of money. There are 3 types of value proposition, the full benefits, the favorable points and differences that the clients perceive (Hassan, 2012).

The proposed variables were statistically analyzed and measured by using the Likert scale, in order to identify the perception regarding the benefits offered to the existing and potential customers of the entrepreneurs who own an online store. This perception is very important because we can identify the key points that can be improved by digitalization, so as to provide an easier, less costly experience.

The current state of digitalization affects the revenue of online stores trough online advertising. Digitalization is required in advertising campaigns, according to Bleier \& Eisenbeis (2015), the clickthrough rate in the survey conducted increased by $27 \%$ (from $.40 \%$ to $.51 \%$ ) as a result of a higher degree of personalization of commercials and a higher interest on customer preference approach by analyzing past online acquisitions (Bleier \& Eisenbeis, 2015). 


\section{2nd International Academic Conference on MANAGEMENT and ECONOMICS}

Lee \& Ha (2018) consider that prefabricated applications and Application Programming Interface (API) services reduce the barriers of bringing customers new products and services more quickly by integrating solutions and services (Lee \& Ha, 2018).

Jennifer Xue considers that together with Business Intelligence (BI) and synchronized application functionalities, better and faster decision can be made. For this purpose, only software applications that provide real-time data collection and reporting should be adopter. Integrating BI with data is crucial for ensuring a prompt approach to problems (Xue, 2018).

Krishna \& Singh concluded in a study that IT infrastructure and company size play an important role in adopting B2B ecommerce systems. Larger organizations have large investment capacity and risks, and are therefore more open to adopting such changes (Krishna \& Singh, 2018).

The study conducted by Cenamor et al. (2017) in the field of manufacturing industry, concludes that all actors involved in a new architecture need to know their role and make a firm commitment to working together to make use of an information module. Thus, the study explains a platform type approach that offers the potential to transform service delivery challenges into opportunities to overcome competitors' performance (Cenamor, et al., 2017).

Considering these results of previous researches, a complex questionnaire was designed according to the research objectives, which was applied online to the decision people in the target group.

\section{Results}

As a result of the research, Table 1 shows a summary of the participants in this quantitative research.

Table 1: Profile of online stores that participated in the study

\begin{tabular}{|l|l|}
\hline Sample features & Values \\
\hline Number of respondents & 105 people \\
\hline Number of processed orders per month & 2.8913 \\
\hline Average number of orders processed per month & 275 per online store \\
\hline Number of employees involved in the online store activity & 796 \\
\hline Average number of employees per online store & 7.58 per online store \\
\hline Number of products listed in the online stores included in the study & 253.505 \\
\hline Average number of products in the online store offer & 2.414 per online store \\
\hline Online stores that have a pickup option from the headquarters & $39 \%$ \\
\hline Online stores that deliver nationally & $98.1 \%$ \\
\hline Online stores that deliver internationally & $21 \%$ \\
\hline
\end{tabular}

Source: Authors' own research

Following SPSS data processing, Table 2 shows that a case was excluded because it was not statistically representative. 
Table 2: Data processing summary

\begin{tabular}{|c|c|c|c|}
\hline & & $\mathrm{N}$ & $\%$ \\
\hline \multirow{3}{*}{ Cases } & Valid & 105 & 99,1 \\
\hline & Excluded $^{\mathrm{a}}$ & 1 &, 9 \\
\hline & Total & 106 & 100,0 \\
\hline
\end{tabular}

a. Cases deleted by all variables included in the research.

Source: Authors'own research

Table 3 shows the Cronbach Alpha coefficient and the Cronbach Alpha coefficient based on standardized elements. According to IBM, Cronbach Alpha identifies covariates between elements, while while Cronbach Alpha based on standardized elements uses inter-asset correlations (IBM Support, 2016). A coefficient value of 0.890 is a good value, indicating that the variables included in the research have internal consistency, the correlations are good to excellent, among the 37 variables included in the quantitative research carried out.

Table 3: Statistical validity result

\begin{tabular}{|c|c|c|}
\hline Cronbach Alpha & $\begin{array}{c}\text { Cronbach Alpha based on standardized } \\
\text { items }\end{array}$ & N of variables \\
\hline, 890 &, 896 & 37 \\
\hline
\end{tabular}

Source: Authors'own research

Table 4 summarizes the results of the analyzed data and their correlation with the total results of the processed data.

Table 4: Statistics summary of variables

\begin{tabular}{|l|l|l|l|l|l|l|c|}
\hline & Average & Minimum & Maximum & Interval & Max/Min & Variation & $\begin{array}{c}\text { No. of } \\
\text { variables }\end{array}$ \\
\hline Average Variables & 4,657 & 2,676 & 6,181 & 3,505 & 2,310 & 1,100 & 37 \\
Variation & 4,124 & 2,207 & 6,583 & 4,376 & 2,982 & 1,016 & 37 \\
Covariation variable - variable &, 741 &,- 793 & 3,962 & 4,755 & $-4,999$ &, 406 & 37 \\
Correlation variable - variable &, 188 &,- 163 &, 931 & 1,094 & $-5,704$ &, 027 & 37 \\
\hline
\end{tabular}

Source: Authors' own research

Variables that have a strong correlation were selected from the analyzed values, in Table 5, the strongest independent statistics were highlighted. 
Table 5: Independent correlated variables contributing to value creation

\begin{tabular}{|l|l|l|l|}
\hline No. & Variable 1 & Variable 2 & Pearson Coefficient \\
\hline 1 & V53.Improved_billing_speed & V23.Products_update_optimization & 0,657 \\
\hline 2 & V44.Communication_automation & V51.Adding_products_costs & 0,618 \\
\hline 3 & V53.Improved_billing_speed & V18.Prodcuts_adding_optimization & 0,61 \\
\hline 4 & V32.Fast_shipping & V35.Warranty_support_services & 0,594 \\
\hline 5 & V53.Improved_billing_speed & V51.Adding_products_costs & 0,576 \\
\hline 6 & V32.Fast_shipping & V33.Reduced_products_price & 0,572 \\
\hline 7 & V50.Products_update_costs & V44.Communication_automation & 0,562 \\
\hline 8 & V10.AWB_automation & V49.Billing_automation & 0,543 \\
\hline 9 & V32.Fast_shipping & V31.Real_time_stocks & 0,527 \\
\hline 10 & V44.Communication_automation & V23.Products_update_optimization & 0,521 \\
\hline 11 & V32.Fast_shipping & V34.Consultin_services & 0,517 \\
\hline 12 & V44.Communication_automation & V53.Improved_billing_speed & 0,516 \\
\hline
\end{tabular}

Source: Authors' own research

The 12 identified correlations identified, with a value greater than 0.5 , indicate that the improvement of the billing rate is correlated with the optimization of products updating, thus it can be assumed and later researched that this representative correlation is the consequence of the fact that the employees who issue invoices also deal with product updates in the online stores. The cause of this t can also be the situation where there is a strong correlation between the variables V44 / V51 and V53 / V18 variables. Respondents provided answers so that we could see that those who think they are chosen by the customer for shipment are also elected to provide support and warranty services, reduced product prices, real-time inventory display, and consulting services. Thus, the value proposition indicates strong correlations between the fast delivery of products and these factors. For V32 / V35, V32 / V33, V32 / V31, V32 / V34 correlations, the correlation between V53 and V51 is also considered atypical and probably is due to the multiple responsibilities of online stores employees. The same type of atypical linkage can also be observed with V50 / V44, V44 / V23, V44 / V53 sets of variables. The correlated responses presented in variables V10 and V49 indicate that those who have implemented the automation of bills usually have the implementation of automatic AWB issuance.

For nominal variables, a descriptive analysis of the collected data was performed. It has the role of dividing the initial sample according to certain criteria in order to identify a necessity and specially to observe a pattern of technology used by the entrepreneurs in the online commerce industry. The variables shown in Figure 1 were selected from the underlying processes that define an online sale. Thus, in the following figure we can see the adoption rate of online communication by respondents, the way they register and update their products in the store, the type of activity they perform when receiving an online order, and the automation related facilities that they already have. The V14, V15 and V16 variables indicate that very few automations are used to add products, and even if these 
automations are used, some users also list products manually. In V19, V20 and V21 we have similar a behavior. With these two behaviors we can assume that in most cases, although automations have replaced manual processing, it has not been completely eliminated. For manual or automated orders, an important trend can be seen. Even though $68.6 \%$ of respondents say they process orders automatically, there is $78.1 \%$ of respondents who say they don't automatically process orders. Automatic confirmation of orders does not exclude manual order processing, but this indicates that most respondents process both incoming and outgoing orders manually. The same behavior is also identified when invoices are issued. In this situation it can be considered that automations, however perfect they may, cannot replace manual processes. V10 determines whether there are automated AWB issuers, in which case $72.4 \%$ have already implemented this type of automation for delivery documents.

Figure 1: Nominal variable results

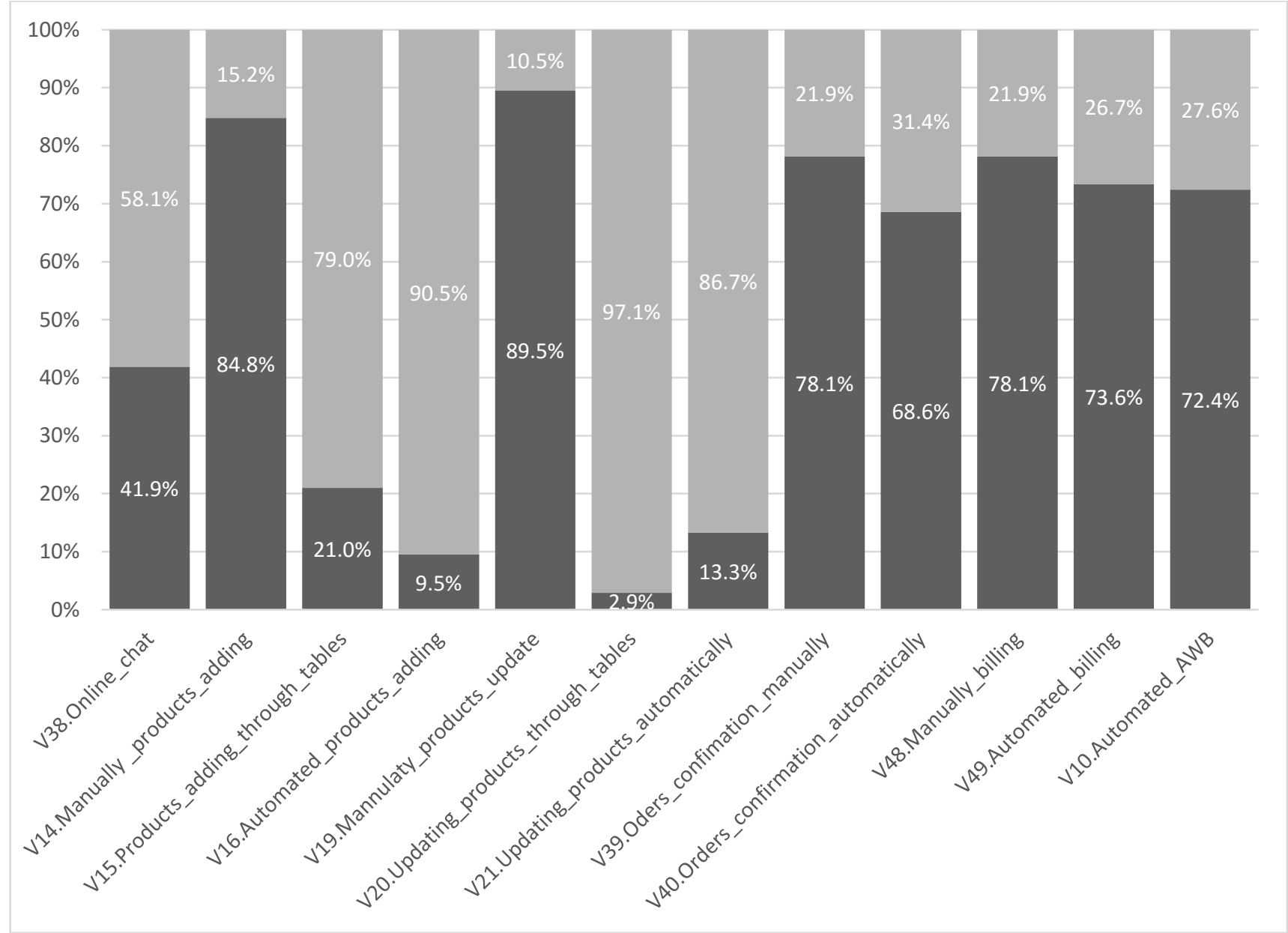

Source: Authors' own research 


\section{Conclusion}

For the collected data where a unified scale was not used, a descriptive analysis on value thresholds was made because a statistical correlation with one of the chosen factors was not possible. Figure 2 shows the distribution of the number of employees working for an online store. As it can be observed in Figure 2, these businesses are very small business.

Figure 2: Distribution of stores surveyed by number of employees

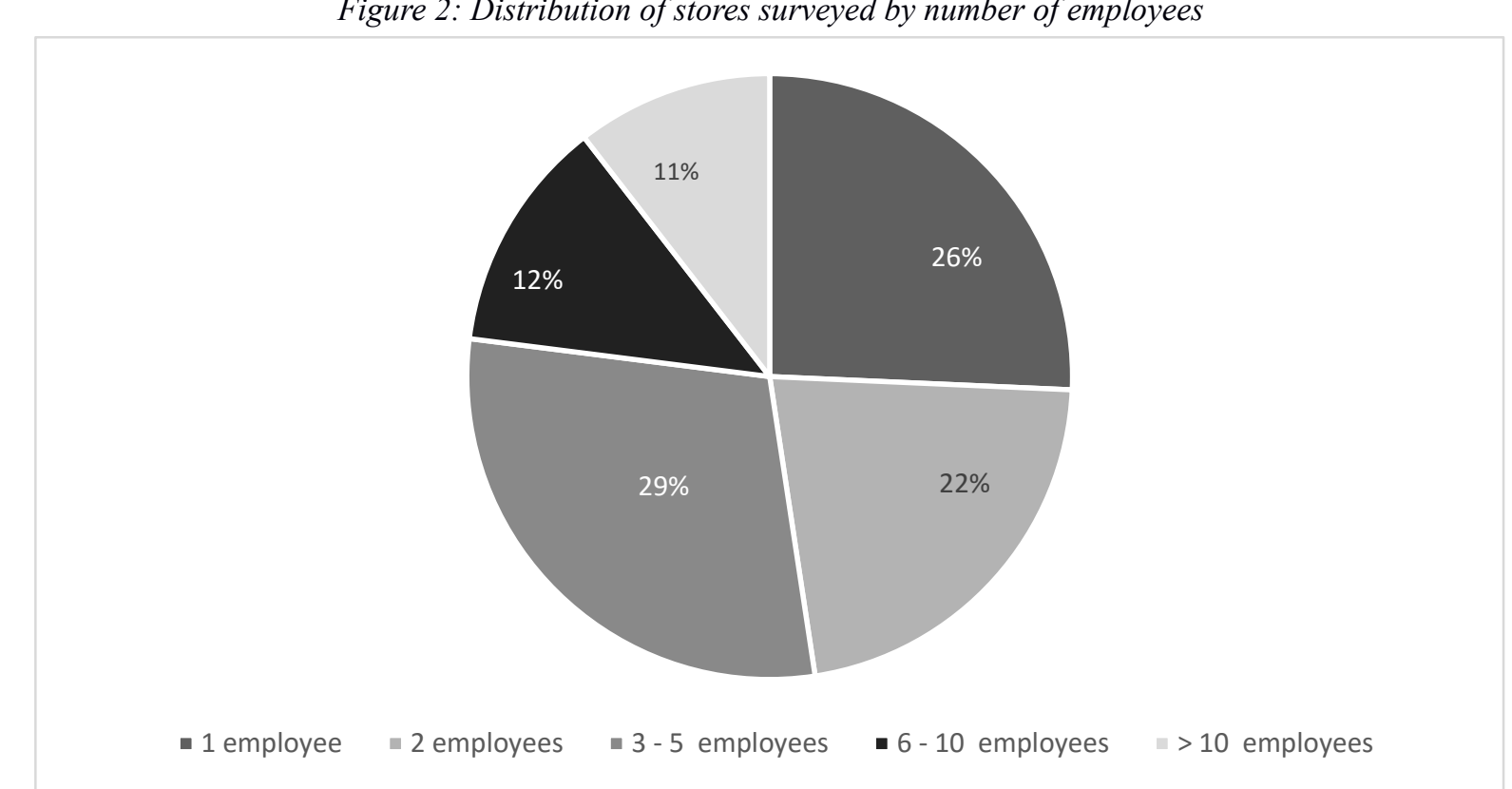

Source: Authors' own research

The complexity of an online store and its success in the market is also represented by the variety of the offer, depending on the size of the offer presented, it requires different automation solutions and can perform differently. Figure 3 shows the distribution of stores on value thresholds. 
Figure 3: Number of products in the online stores analyzed

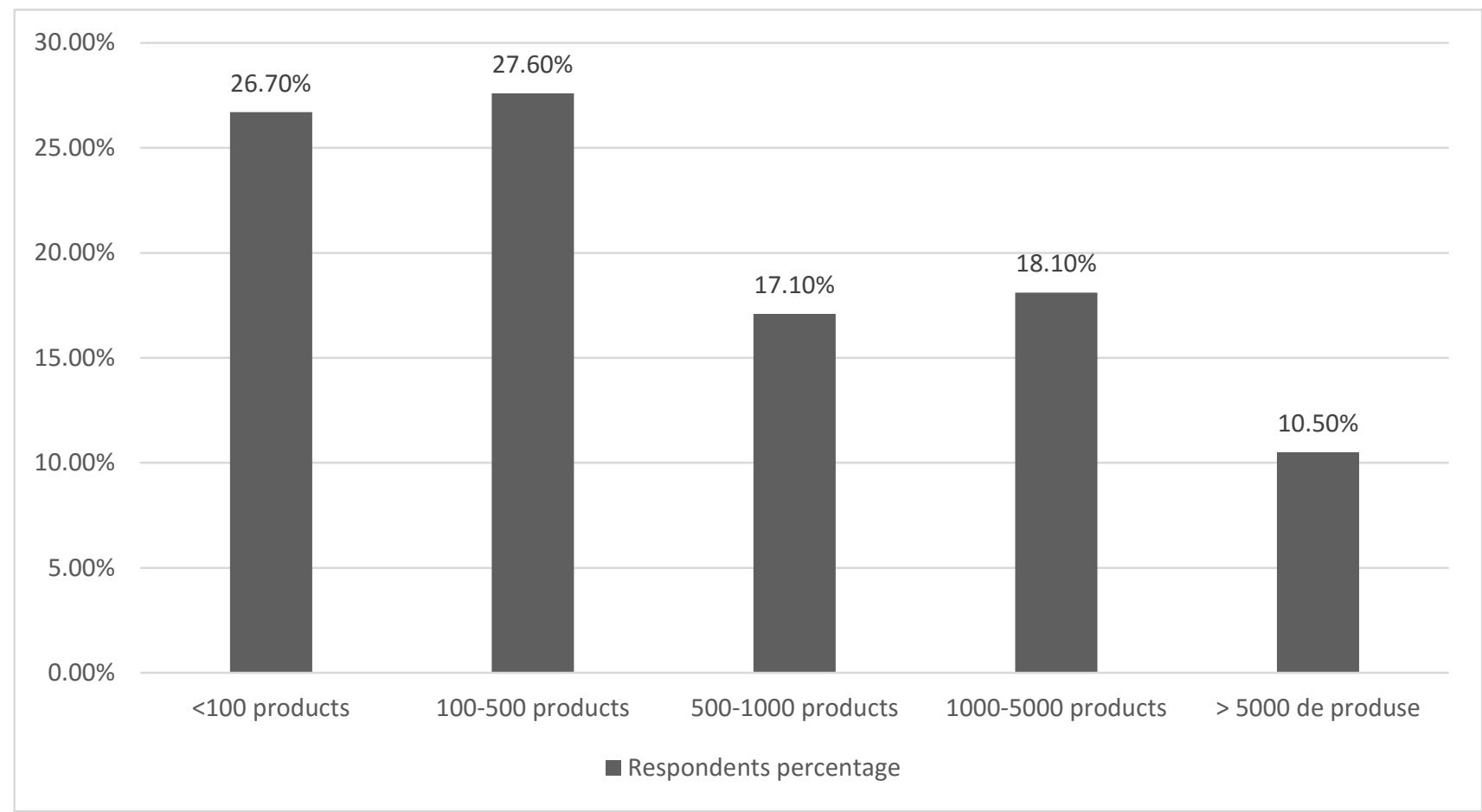

Source: Authors'own research

Since the study has collected data from any online store owner, it is important to have a tiebreak. As noted, many stores are operated by 1 employee, representing $26 \%$ of respondents or 2 employees representing a total of $48 \%$ of participating stores. Depending on the investment, automation and company dynamics, the number of orders may also vary. In this case, there have been ranges to identify the status of the received orders on average per month, the results obtained are in Figure 4. 
Figure 4: Distribution of stores by number of monthly ord

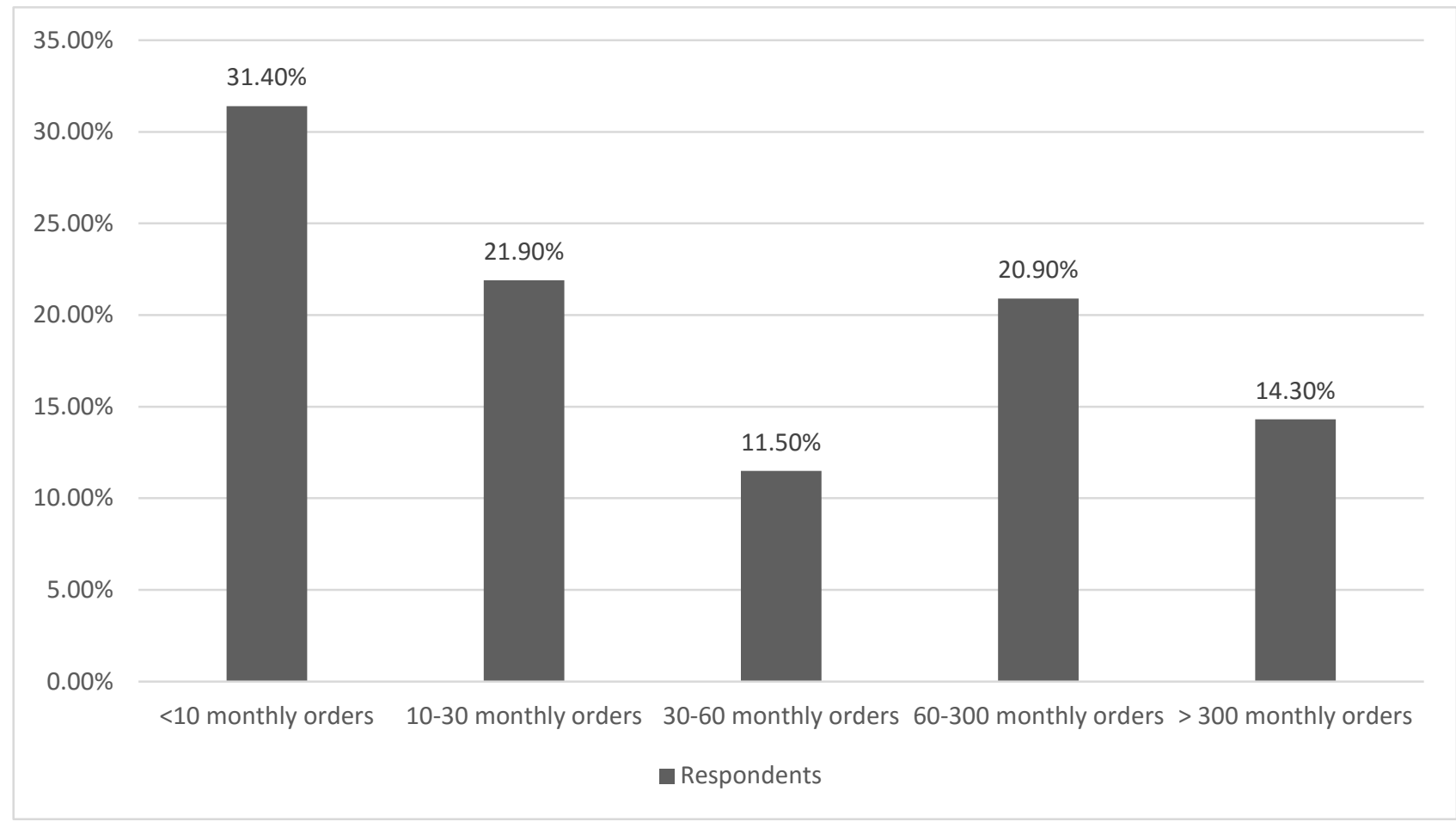

Source: Authors' own research

Steiber \& Alänge (2016) believe that IT-related domains, such as software, electronics, telecom, e-commerce, social networks and mobile technologies, have created the need for constant innovation as technology is changing rapidly and companies become flexible and adaptable quickly (Steiber \& Sverker, 2016). This need for innovation can quickly push any company to become more efficient in the current economy. For all these changes, the learning process should be included in any discussion, a recent study finds that an organization that provides employees with courses increases the possibilities to implement successful implementations in business digitization processes (Maditinos, et al., 2014).

In the case of online stores analyzed, there is a clear tendency to have a reduced number of employees. Thus, the need to digitalize every available online system is growing and, on the other hand, human resource specialization is diversified to allow the online store to function economically efficiently and to bring added value to customers. On the other hand, it can be noticed that there are already solutions to digitalize certain processes, according to the results, we can see representative examples of online stores that have taken steps in this regard. The value proposition can be enhanced with digital systems, so a company can quickly publish the offer and process multiple orders with fewer employees and lower operating costs. 


\section{Acknowledgment}

This work has been funded by the European Social Fund from the Sectoral Operational Programme Human Capital 2014-2020, through the Financial Agreement with the title "Scholarships for entrepreneurial education among doctoral students and postdoctoral researchers (Be Antreprenor!)", Contract no. 51680/09.07.2019 - SMIS code: 124539.

\section{References}

[1] Briscoe, G.:Digital Ecosystems. PhD thesis, Imperial College London, London, United Kingdom, (2009)

[2] Richard, P. J.;Devinney, T. M.; Yip, G. S.; Johnson, G.: Measuring Organizational Performance: Towards Methodological Best Practice, Journal of Management, Vol. 35 (2009), No. 3, pp. 718-804, DOI: 10.1177/0149206308330560

[3] Hassan, A.: The Value Proposition Concept in Marketing: How Customers Perceive the Value Delivered by Firms - A Study of Customer Perspectives on Supermarkets in Southampton in the United Kingdom, International Journal of Marketing Studies, Vol. 4 (2012), No. 3, pp. 68-87, DOI:10.5539/ijms.v4n3p68

[4] Bleier, A.; Eisenbeis, M.: The Importance of Trust for Personalized Online Advertising, Journal of Retailing, Elsevier, Vol. 91 (2015), No. 3, pp 390-409, DOI: 10.1016/j.jretai.2015.04.001

[5] Lee, K.; Ha, N.:AI Platform to Accelerate API Economy and Ecosystem, International Conference on Information Networking, pp. 848-852, DOI10.1109/ICOIN.2018.8343242, Chiang Mai, Thailand, January 2018, IEEE, (2018)

[6] Xue, J.: Startus Magazine. [Online] Available at: https://magazine.startus.cc/automated-ecommerce-is-the-future-of-e-commerce/ [Accessed 19-01-2018].

[7] Krishna, N.; Singh, J.: Factors affecting b2b e-commerce adoption decision: an analysis of indian textile industry, Academy of Marketing Studies Journal, Vol. 22 (2018), No. 2, pp. 1-9, ISSN: 1528-2678-22-2-140

[8] Cenamor, J.,;Rönnberg Sjödin, D.; Parida, V.: Adopting a platform approach in servitization: Leveraging the value of digitalization, International Journal of Production Economics, Vol. 192 (2017), pp. 54-65,: DOI: 10.1016/j.ijpe.2016.12.033

[9] IBM Support, 2016. IBM Support. [Online] Available at: http://www01.ibm.com/support/docview.wss?uid=swg21479940 [Accessed 01-01-2019].

[10] Steiber, A.; Sverker, A.: The Silicon Valley Model, Management for Entrepreneurship, Springer, ISBN-13: 978-3319249193, (2016).

[11] Maditinos, D.;Chatzoudes, D.; Sarigiannidis, L.: Factors affecting e-business successful implementation, International Journal of Commerce and Management, Vol. 24 (2014), No. 4, pp. 300-320, DOI: 10.1108/IJCoMA-07-2012-0043 